\title{
Many Facets of Dynamic Plasticity in Plants
}

\author{
Xiaodong Yang and Sally A. Mackenzie \\ Departments of Biology and Plant Science, The Pennsylvania State University, University Park, \\ Pennsylvania 16802, USA \\ Correspondence: sam795@psu.edu
}

The evolutionary processes that transitioned plants to land-based habitats also incorporated a multiplicity of strategies to enhance resilience to the greater environmental variation encountered on land. The sensing of light, its quality, quantity, and duration, is central to plant survival and, as such, serves as a central network hub. Similarly, plants as sessile organisms that can encounter isolation must continually assess their reproductive options, requiring plasticity in propagation by self- and cross-pollination or asexual strategies. Irregular fluctuations and intermittent extremes in temperature, soil fertility, and moisture conditions have given impetus to genetic specializations for network resiliency, protein neofunctionalization, and internal mechanisms to accelerate their evolution. We review some of the current advancements made in understanding plant resiliency and phenotypic plasticity mechanisms. These mechanisms incorporate unusual nuclear-cytoplasmic interactions, various transposable element (TE) activities, and epigenetic plasticity of central gene networks that are broadly pleiotropic to influence resiliency phenotypes.

$\mathrm{C}$ rop improvement strategies to address food security demands have relied on a diversity of germplasm as a resource from which to derive plant stress tolerance in breeding. However, with increasing environmental challenges, rising soil salinity and encroaching desertification, annual climate instability, and drought and flooding threats of increasing frequencies, additional knowledge is needed to interpret plant environmental sensing and response behaviors and their amenability to direct manipulation. Toward these ends, emerging data, and a careful rereading of past research, provide valuable insight into the multiplicity and interconnections of adaptive strategies in plants that serve to enhance their environmental resiliency. Here, we review four of the areas in which epigenetic and environmental sensing mechanisms have integrated with genetic plasticity to broaden intraspecific adaptation in plants.

\section{REPRODUCTIVE PLASTICITY}

In an agricultural context, plant fruit and seed production can define crop yield. Consequently, factors associated with optimizing yield have been subjected to intense selection. Plant reproductive behavior within a high-density, intensive agricultural system is often modified relative to a species' natural habitat (in situ) reproductive strategies to accommodate breeding schemes (discussed in Altieri and Merrick 1987). This is particularly the case for crops that display predominantly or exclusively self-pollination

Editor: Pamela C. Ronald

Additional Perspectives on Engineering Plants for Agriculture available at www.cshperspectives.org

Copyright (C) 2019 Cold Spring Harbor Laboratory Press; all rights reserved; doi: 10.1101/cshperspect.a034629

Cite this article as Cold Spring Harb Perspect Biol 2019;11:a034629 
under agricultural (ex situ) cultivation (Zuellig et al. 2014). In native ecosystems, capacity for self-pollination safeguards a lineage during plant isolation, but this system of reproduction results in significant inbreeding, so is generally accompanied by incidence of male (pollen) sterility or other mechanisms to facilitate outcrossing and/or genetic recombination. Nuclear male sterility mutations can arise, but generally at sufficiently low frequency to make them minimally influential on gene flow (Willis 1999). Rather, many species display a facultative, reversible system for male sterility that capitalizes on pliancy of the mitochondrial genome, a feature that is distinctive to plants.

"Facultative gynodioecy" is a reproductive system that produces both hermaphrodite and females in a population. The phenomenon arises with the propensity of plant mitochondrial genomes to undergo rearrangement and nonhomologous recombination (Gualberto and Newton 2017). Unlike animal systems, in which mitochondrial genomes are conserved in size and structure, plant mitochondrial genomes are unusually variable in organization and recombinogenic. In Arabidopsis, large (>1000 bp) repeats participate in high-frequency, reciprocal recombination, whereas smaller repeats, from 50 to $500 \mathrm{bp}$ in size, engage in asymmetric DNA exchange events that produce rearrangement of the genome (Davila et al. 2011), as well as substoichiometric shifting events that alter the relative copy number of subgenomic DNA molecules (Arrieta-Montiel et al. 2009). Aberrant recombination activity within plant mitochondria has resulted in introgression of foreign DNA as well as intragenic DNA exchange events that can, collectively, produce dominant mutations (Gualberto and Newton 2017). Many of these aberrant gene configurations, at least those that are retained within plant lineages, condition male sterility. Pollen disruption conditioned by a mitochondrial mutation is termed cytoplasmic male sterility (CMS), a trait that has been used since the 1950s for agricultural purposes to reduce costs in hybrid seed production for numerous crops (Chen and Liu 2014).

Within natural plant populations, CMS mutations can be countermanded by nuclear fertil- ity restorer genes. Modeling the frequency and longevity of population genetic impact attributable to a CMS mutation is a function of the frequency and fitness of male fertility restorer alleles within a given population (Case and Caruso 2010; Caruso et al. 2012; Caruso and Case 2013). What generally goes unnoticed in the development of these nuclear-cytoplasmic models, however, is the influence of environment. The recombinogenic behavior of the mitochondrial genome can be controlled by nuclear genes that are environmentally responsive. In the case of plant-specific nuclear gene MutS HOMOLOG 1(MSH1), for example, mutation or suppression of the gene activates recombination at $\sim 50$ mitochondrial repeats and leads to genomic substoichometric shifting in Arabidopsis (Davila et al. 2011) as well as Brassica juncea (Zhao et al. 2016) and other species (Sandhu et al. 2007). In a wild-type plant, suppression of MSH1 can lead to male sterility (Sandhu et al. 2007; Zhao et al. 2016); however, altered expression of $\mathrm{MSH} 1$ in a cytoplasmic male sterile line can cause reversion to fertility (Zhao et al. 2016; N Zhao, L Zhang, X Yang, et al., unpubl.), reflecting a reversible dynamic inherent to mitochondrial genomic rearrangement. Steadystate transcript levels for $M S H 1$ in reproductive tissues are suppressed under abiotic stress conditions that include heat, cold, salt, drought, and high light (Shedge et al. 2010; Xu et al. 2011; Virdi et al. 2016; Kenchanmane Raju et al. 2018), but markedly amplified by changes in sucrose levels (Hruz et al. 2008; N Zhao and $\mathrm{X}$ Yang, pers. comm.). Thus, the mitochondrial genome is conditioned for greater recombination during stress conditions and stabilized by enhanced sucrose availability. The flowering and fertilization process involves changes in sugar transport to accommodate the energy-intensive process of seed development following successful pollination. During conditions of plant isolation and cross-pollination failure, the absence of these sugar signals can serve as a sufficient cue to alter MSH1 expression, leading to lowfrequency reversion to pollen fertility and successful self-pollination. Alternatively, successful early pollination by a maintainer genotype and enhanced sucrose transport stabilize the mito- 
chondrial genome and permit transmission of the male sterility trait (Zhao et al. 2016; N Zhao, X Yang, and S Mackenzie, unpubl.).

"Apomixis" is a second reproductive strategy that shows unusual plasticity in plants, representing a series of inherited mechanisms for asexual reproduction by clonal seeds that bypass meiosis and egg cell fertilization. In the apomict, meiotic mother cells or ovule somatic cells produce unreduced products that divide mitotically to form the embryo sac (Carman 1997). The phenomenon of apomixis is relatively widespread, occurring naturally in more than 120 genera of angiosperms in nearly 40 families, with $\sim 75 \%$ of apomicts identified in Asteraceae, Rosaseae, and Poaceae (Carman 1997; Asker and Jerling 2017). Agriculturally, the apomictic trait permits genetic fixation of a desirable genotype, and so has been the subject of intensive investigation.

In most cases, species with this trait are facultatively apomictic but also undergo sexual reproduction to some extent (Koltunow and Grossniklaus 2003). Apomixis is most often observed in polyploid species, but is also observed in some diploids, so that polyploidy is not required for the phenomenon. The apomictic abnormalities associated with gametogenesis are thought to arise by ectopic expression of developmental pathways caused by multiple genome asynchrony in polyploids (Carman 1997). Variable alterations in reproductive development can result in apomixis. During early ovule ontogeny, it is possible for sexual and apomictic development to occur together within the same ovule or in multiple ovules of a single plant. These observations suggest that apomixis arises by dysregulation of various developmental steps of sexual reproduction (Koltunow and Grossniklaus 2003). For example, unfertilized ovules produce somatic cells that can form embryos in the case of adventitious embryony. Alternatively, gametophytic apomixis occurs from an unreduced egg cell that forms an embryo by variously altered processes (Rodriguez-Leal and Vielle-Calzada 2012).

Aposporous apomixis in Hieracium praeltum, producing $2 \mathrm{n}$ gametophytes from vegetative cells, is shown by deletion studies to involve at least two genetic loci, LOSS OF APOMEIOSIS (LOA) and LOSS OF PARTHENOGENESIS (LOP). LOA is thought to participate in apospory and suppression of sexual megaspore development, whereas $L O P$ may function in the separate development of embryo and endosperm (Koltunow et al. 2011). Loss of the two loci restores sexual development, indicating that sexual reproduction is a default pathway that can be interrupted by apomictic processes.

There is increasingly compelling evidence that apomixis is an environmentally responsive function that is epigenetically controlled (Grimanelli 2012). In species that undergo both sexual and apomictic reproduction, the balance between these two pathways can be influenced by oxidative stress conditions (Nedelcu et al. 2004). Numerous species have shown apomixis frequency to be responsive to changes in photoperiod (Knox 1967; Evans and Knox 1969; Klatt et al. 2016), and to abiotic stress conditions (Gounaris et al. 1991; Rodrigo et al. 2017).

Female gametogenesis appears to be regulated by epigenetic mechanisms that participate in sexual versus apomictic development. In Arabidopsis, female gametophyte development from sporophytic cells in the absence of meiosis can occur in AGO9 dominant mutants (OlmedoMonfil et al. 2010), implying a role for the small RNA and RNA-dependent DNA methylation pathways in distinguishing sexual from aposporous development. Similarly, the AGO104 gene, another component of the small RNA pathway that influences centromeric chromatin, participates in the production of functional unreduced gametes and apomixis-like behaviors in maize (Singh et al. 2011). In dandelions, interploidy crosses that produce diplosporous progeny undergo changes in genome-wide methylation patterning (Verhoeven et al. 2010) and appear able to confer epigenetic abiotic stress signaling transgenerationally (Morgado et al. 2017). Coupled with earlier evidence of epigenomic reprogramming during gametogenesis in plants (Wang and Köhler 2017), these observations suggest that epigenetic programming of gamete "specification" occurs as well, representing an underrecognized plant developmental decision point in response to environmental change. 
X. Yang and S.A. Mackenzie

\section{ORGANELLAR GENE NEOFUNCTIONALIZATION}

Protein multifunctionalization is an evolutionary process that serves to enhance phenotypic plasticity as plants expand their growth range in variable environments (Fig. 1). Two examples of this phenomenon share similarities in features and in their unexpected functional versatilities.

The plastid is a subcellular compartment that is unique to the plant kingdom and shows a range of behaviors important to adaptation, including photosynthesis, carbohydrate storage in stems and roots, phytohormone biosynthesis, pigment synthesis in flowers and fruits, and abiotic and biotic stress response. Evolution of novel plastid types and functions relies on the amenability of nuclear-encoded proteins to multitargeting and spatiotemporal regulation of expression. An example of this adaptability is the recent discovery of the "sensory" plastid, a plastid type that is localized to vascular parenchyma and epidermal cells, is $\sim 30 \%$ the size of a mesophyll chloroplast, and displays distinctive proteome enrichment in stress-response proteins (Virdi et al. 2016; Beltrán et al. 2018). Genes that encode sensory plastid-specific proteins appear to contain promoters under spatiotemporal regulation (Virdi et al. 2016). Circumstances like this provide an ideal opportunity for protein multifunctionalization.

Plastids contain a nucleoid subcompartment that harbors the plastid genome and DNA replication, transcription, and RNA-processing functions (Sato et al. 2003; Melonek et al. 2016). Consequently, the plastid nucleoid has the capability of responding to environmental cues that include nuclear signals to alter photosynthesis, ROS-mediated cellular stress signals, and developmental cues for plastid redifferentiation. Protein composition of the nucleoid is variable across plant lineages, providing evidence of its repatterning over evolution (Pfalz and Pfannschmidt 2015; Kobayashi et al. 2016). Whirly proteins comprise a small family (Desveaux et al. 2005) of nucleoid-localizing proteins that

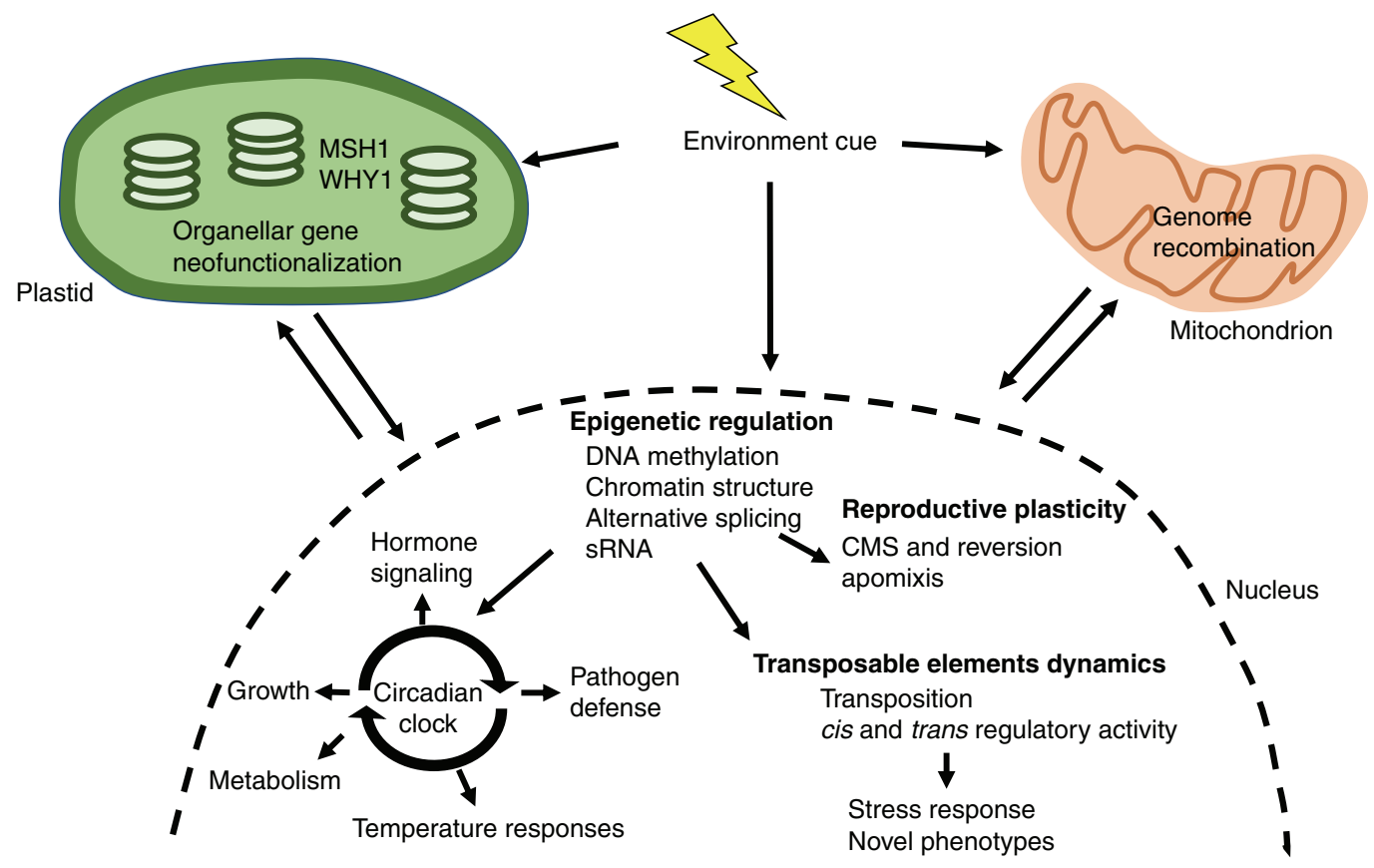

Figure 1. Diagrammatic overview of nuclear epigenetic and organellar components of phenotypic plasticity in plants. CMS, Cytoplasmic male sterility. 
have adapted through multifunctionalization in plants. The proteins localize not only to plastids, but to the nucleus and/or mitochondria (Desveaux et al. 2005; Isemer et al. 2012).

Whirly proteins in Arabidopsis bind singlestranded DNA/RNA and may have originated, early in their evolution, to provide organellar genome stability by suppressing illegitimate recombination at small DNA regions of microhomology (Marechal et al. 2009; Cappadocia et al. 2010). Consistent with this hypothesis, analysis of WHY-GFP fusions show that the WHIRLY1 protein localizes to the plastid nucleoid, and the Whirly family of proteins target both mitochondria and plastids (Krause et al. 2005). Yet, Melonek et al. (2010) provide evidence that only a portion of WHY1 is nucleoid-bound, and the protein can also be found associated with intron-containing transcripts (Melonek et al. 2010). Moreover, in maize, WHY1 appears to participate in splicing of the atpF group II intron and may be essential for assembly of the large ribosomal subunit (Prikryl et al. 2008), underscoring the importance of these proteins in organelle biogenesis.

Remarkably, recombinant WHY1 protein has the capacity to translocate from chloroplasts to the nucleus (Isemer et al. 2012), and WHY1 appears to function as a nuclear transcription factor in salicylic acid signaling (Desveaux et al. 2004, 2005). Additionally, the protein appears to function in the nucleus to influence telomere length homeostasis (Yoo et al. 2007). It has been suggested that WHY1 participates in environmental sensing, functioning in chloroplast-to-nucleus retrograde cross talk to facilitate abiotic-biotic stress tolerance following changes in redox state of the photosynthetic electron transport chain (Foyer et al. 2014).

A second multifunctional organellar protein has been identified that similarly appears to enhance phenotypic plasticity in response to environmental change. MUTS HOMOLOG 1 (MSH1) was initially identified in Arabidopsis to be a plant-specific, mitochondrially targeted protein that suppresses illegitimate recombination (Abdelnoor et al. 2003, 2006). More extensive study of its mitochondrial association showed that MSH1 functions in the induction/ suppression of CMS, as described earlier. However, the MSH1 protein also targets to plastids, and its transcription is regulated to permit specific accumulation in epidermal, vascular parenchyma, and reproductive tissues that contain sensory plastids (Virdi et al. 2016).

Whereas suppression of mitochondrial MSH1 influences mitochondrial genome configuration, disruption of the plastid form results in epigenomic reprogramming of the plant $(\mathrm{Xu}$ et al. 2012; Virdi et al. 2015). The msh1 phenotype includes genome-wide methylome repatterning (Virdi et al. 2015) and altered expression of numerous abiotic, biotic, phytohormone, and circadian clock networks (Shao et al. 2017), resulting in enhanced tolerance to high light (Xu et al. 2011), heat (Shedge et al. 2010), cold (Kenchanmane Raju et al. 2018), drought (Virdi et al. 2016), and salt (Kenchanmane Raju et al. 2018). Within sensory plastid-containing cells, the $m s h 1$ phenotype includes changes in expression of DNA methylation and histone-modifying genes, as well as calcium and mitogen-activated protein kinase (MAPK) signaling pathways (Beltrán et al. 2018).

RNAi suppression of MSH1 is followed by segregation of the RNAi transgene to produce transgene-null segregants that retain msh1 "memory" (Xu et al. 2012; Virdi et al. 2015). The memory phenotype, involving delayed flowering, delayed maturity transition, reduced growth rate, altered circadian clock, and enhanced stress responsiveness, is heritable indefinitely (Xu et al. 2012; Virdi et al. 2015). Reciprocal crossing of the "memory" lines with wild-type produces plant lineages with measurable growth and yield enhancement and reduced genotype $\mathrm{x}$ environment interaction effects, a phenomenon recapitulated in both monocot and dicot crop species (De La Rosa Santamaria et al. 2014; Virdi et al. 2015; Yang et al. 2015; Raju et al. 2018). These MSH1 features are epigenetic, reproducible, and conserved within a range of plants to influence phenotypic resiliency to environmental stress.

What is striking about the MSH1 and WHY1 examples of protein multifunctionalization are their seemingly similar evolutionary features. Both represent nuclear genes encoding 
organellar proteins that display DNA-binding and regulatory functions. Both proteins show evidence of multitargeting, nucleoid and thylakoid localization, redox influence, and participation in plant environmental adaptation. These similarities imply that there may be additional multifunctional proteins emerging from future sensory plastid and nucleoid proteome studies. Similarly, these parallels imply that plant mitochondria and plastids, as highly versatile organelles in plants, serve central roles in phenotypic plasticity for rapid adaptation functions of the plant.

\section{TRANSPOSABLE ELEMENT DYNAMICS}

Transposable elements (TEs), or transposons, are mobile genetic elements found in virtually all genomes sequenced to date. Together with genome polyploidization events during plant evolution, TEs serve to greatly enlarge plant genomes in size (Wendel et al. 2016). Although TE families are numerous and highly varied, expansion within a plant lineage is often attributable to a single or small number of TE families (El Baidouri and Panaud 2013; Vicient and Casacuberta 2017). In Arabidopsis, $\sim 18 \%$ of the genome is comprised of TEs, whereas $85 \%$ of the maize genome displays homology with TEs, with most other plant species falling somewhere between (Kaul et al. 2000; Oliver et al. 2013). Among closely related species, such as Sorghum bicolor versus Zea mays, the difference in TE composition is significant, with TEs accounting for $~ 65 \%$ of the sorghum genome (Kaul et al. 2000; Oliver et al. 2013; Hirsch and Springer 2017). The vast disparities in TE numbers per genome is, in part, caused by an equilibrium between TE gain and loss processes. TE loss from a genome occurs through unequal homologous and illegitimate recombination activity, which appears to be fairly efficient because, in most plant genomes, the majority of long terminal repeat (LTR) retrotransposons comprise relatively recent insertions (Bennetzen and Wang 2014).

A significant proportion of TEs are associated with genes; $36 \%$ of Arabidopsis genes contain a TE within a $1 \mathrm{~kb}$ distance, whereas this number goes to $86 \%$ in maize (Li et al. 2015).
Recent studies show evidence that TEs play beneficial roles for plant genome evolution and chromatin behavior. Remarkably, TE presence or insertion within genes is often tolerated and does not necessarily disrupt gene function (Bera et al. 1995; Weiss 2013; West et al. 2014; Sahebi et al. 2018). Evidence suggests that TEs factor prominently in plant-environment interaction, phenotypic plasticity, and as a driving force of evolution. These functions play out in three primary ways.

\section{TEs as Mobile Elements}

The traditional role attributed to TEs is as important sources of accelerated mutation frequency. Their activity in high-frequency mutation occurs most often under stress conditions, generating genetic diversity that is subject to natural selection. As with any type of mutation, TE-associated activity can be harmful, causing genome instability, inversions, and deletions (Mieczkowski et al. 2006; Zamudio and Bourc'His 2010; Lee et al. 2015). However, a significant number of plant genes have been derived from TEs through exaptation, in which TE regulatory or coding sequences that previously functioned in transposition activities now provide adaptive advantage to the host (Feschotte and Pritham 2007; Hoen and Bureau 2012). TEs also participate in the evolution of promoter and intron sequences (Zhao et al. 2016).

Exapted TEs are thought to benefit plants in the process of environmental adaptation. New traits may emerge via element transposition under stress conditions, with beneficial traits retained during directional selection. Some proportion of TE mutations will become fixed in a population, participating as potential networks of coordinate DNA-binding sites to comprise stress adaptive features, and finally undergoing immobilization and full co-opting by the host genome (Joly-Lopez and Bureau 2018). Evidence in support of this hypothesis by reverse genetics and phenomics shows that mutations within exapted TEs in Arabidopsis produce novel plant phenotypes under stress conditions, and affirm participation of exapted TEs in plant responses to phosphate limitation, high salt con- 
Plasticity in Plants

centration, freezing temperatures, and arsenic toxicity (Joly-Lopez et al. 2017).

\section{TEs in Gene Regulation}

Beyond promotion of accelerated genome mutation, TEs are a rich resource of regulatory activities, including cis regulation mediated by regulatory elements containing TEs and trans regulation mediated by TE-produced noncoding RNAs and proteins at both transcriptional and posttranscriptional levels (Chuong et al. 2017). TEs often contain tissue-specific promoter activity or stress-responsive elements, affording the ability to adjust transcription in different tissues or under different environmental conditions, activities that can pass through to nearby genes (Naito et al. 2009; Guio et al. 2014; Bouttier et al. 2016; Chuong et al. 2016). In a genomewide study of transcriptional response during heat stress, conducted in ten ecotypes of Arabidopsis, 203 of 3822 tested TEs showed significant differential expression in response to heat stress (Barah et al. 2013). Studies of the stress-induced transcriptome and transposon proximity to genes in maize showed evidence of strong correlation between TE insertions and stressresponsive gene up-regulation, suggesting that TEs can provide local enhancer activities that stimulate stress-responsive gene activity (Makarevitch et al. 2015). In rice, insertions of a high-copy-number TE, mPing can enhance responsiveness to cold stress in nearby genes (Naito et al. 2009). Agriculture-based selection has been an important contributor to the identification of TE-associated trait acquisition. For example, the LTR retrotransposon Hopscotch is responsible for an insertion in the maize domestication gene teosinte branched 1 ( $t b 1)$ that acts as an enhancer of $t b 1$ expression and partially explains the increased apical dominance phenotype of domesticated maize (Studer et al. 2011). Similarly, research on Sicilian blood oranges (Citrus sinensis) identified a Copia-like retrotransposon insertion in a region adjacent to the MYB transcriptional factor named Ruby, controlling its expression in a cold-dependent manner to modulate anthocyanin production and fruit color (Butelli et al. 2012).

\section{TEs in Epigenetic Regulation}

In plants, cytosine methylation is found in three contexts, $\mathrm{CG}, \mathrm{CHG}$, and $\mathrm{CHH}$, in which $\mathrm{H}$ is $\mathrm{A}$, $\mathrm{T}$, or $\mathrm{C}$. The distribution of these three methylation contexts is uneven, with the majority of $\mathrm{CHG}$ and $\mathrm{CHH}$ associated with silencing and found in repetitive and heterochromatic regions that are highly populated by TEs. Genic regions show higher levels of CG methylation, with CHG methylation localized primarily within introns that contain TEs, supporting a relationship between CHG methylation and TE presence within gene regions. This trend holds true in Arabidopsis (Le et al. 2015), soybean (Kim et al. 2015), maize (West et al. 2014), and several other species in which genome-wide methylome data are available. In maize, $10 \%$ of genes have intragenic $\mathrm{CHG}$ methylation associated with TEs and use H3K9me2 chromatin marks (West et al. 2014).

In Arabidopsis, the heterochromatic state of intronic TEs is critical for proper transcription of associated genes (Le et al. 2015). TEs are subjected to tight regulation imposed by DNA-modifying machinery. Their presence is associated with high-density, localized DNA methylation, small RNA activity, and histonemodification changes that lead to chromatin structure changes, alternative splicing, and gene expression changes that can influence neighboring gene regions as well and alter phenotype (Lisch and Slotkin 2011; Lisch 2013; Oberlin et al. 2017; Sahebi et al. 2018).

Local methylation changes and histone modifications induced by intragenic TEs influence gene splicing or expression patterns. In oil palm, sporadic demethylation of the Karma TE located within an intron of the MANTLED gene results in unmasking of a cryptic splice acceptor site and premature termination signal, causing a mantled fruit phenotype that emerges sporadically in this crop to diminish agricultural value (Ong-Abdullah et al. 2015). In winter wheat, an intragenic TE located in an intron of the VPN1A1 gene shows increased non-CG DNA methylation in response to cold treatment, altering VPN1-A1 expression. Data suggest that the intragenic TE plays a role in vernalization (Khan 
et al. 2013). Similarly, the large CACTA transposon located within an intron of an MYB transcription factor in soybean is subjected to methylation to impact anthocyanin synthase gene expression and seed coat color (Zabala and Vodkin 2014). The TE COPIA-R7 element of Arabidopsis inserted into an intron of diseaseresistance gene $R P P 7$ recruits the histone mark $\mathrm{H} 3 \mathrm{~K} 9 \mathrm{me} 2$ to this locus. H3K9me2 levels at COPIA-R7 affect the choice between two alternative $R P P 7$ polyadenylation sites in the pre-mRNA and, thereby, influence the critical balance between a functional RPP7-coding and a nonfunctional transcript isoform. This outcome decides capacity for response to a specific pathogen (Tsuchiya and Eulgem 2013). In melon, sexual forms are controlled by a balance between andromonoecious locus CmACS-7 and gynoecious locus CmWIP1. Expression of CmWIP1 leads to repression of CmACS-7 and carpel abortion, resulting in the development of unisexual male flowers. Interestingly, the activation of CmWIP1 expression requires DNA methylation changes at its promoter region, which are introduced by insertion of a transposon under natural conditions (Martin et al. 2009).

TE-associated DNA methylation and chromatin alterations often spread to neighboring genes, providing additional regulation of local gene expression (Ahmed et al. 2011; Eichten et al. 2012). One particularly intriguing example of this is ROS1. RNA-dependent DNA methylation and demethylation activities occur within a TE proximal to this DNA demethylating gene to regulate its expression in a feedback loop that serves as an epigenetic rheostat (Williams et al. 2015). In rice, methylome analysis of plants under low-phosphate stress suggests a correlation between low-phosphate stress-induced gene expression and nearby TE methylation status. A model of this process suggests that TEs are a part of phosphate stress-induced gene regulation. Low-phosphate stress-induced genes often colocalize with TEs, and during short-term phosphate stress, low-phosphate stress-induced genes up-regulate. This high expression state is released once the stress is removed, but if the stress is maintained for a longer duration, nearby TEs will activate and attract the methylation machin- ery. Hypermethylation serves to repress highly expressed phosphate stress-induced genes, restoring homeostasis. This phenomenon may represent a species-specific mechanism, because similar phenomena are not observed in parallel analysis of Arabidopsis (Secco et al. 2015).

\section{GENE NETWORK RESILIENCE}

Epigenetically induced resilience in plants has long been known to contribute to phenotypic plasticity, but only in the past few years has the underlying basis for these environmentally responsive processes begun to be understood. Recombinant inbred lines of Arabidopsis that derive from crossing a $d d m 1$ mutant, deficient in cytosine methylation, with an isogenic wildtype line provide a system for investigating the phenotypic implications of epigenomic disruption. Derived DDM1 progeny lineages are altered in cytosine methylation patterning and display transgenerational phenotypic variation (Kooke et al. 2015). These observations provide some of the most compelling evidence of association between DNA methylation patterning and heritable quantitative phenotypic variation, as well as a viable hypothesis for environmental responsiveness of the plant genome. Some proportion of plant phenotypes derived by methylome repatterning are transgenerationally heritable, implying that epigenetic phenomena may participate in preadapting progeny to environmental conditions (Weinhold 2018; Friedrich et al. 2019).

Environmentally responsive gene networks in plants comprise an elegant and sophisticated synthesis of multiple reaction pathways to singular, centralized hubs (Cramer et al. 2011). One central network hub that is integral to the coordination of phenotypic plasticity is the circadian clock (Filichkin et al. 2011). In plants, the clock is comprised of three components, a central oscillator that generates rhythmic output signal, input pathways that entrain the central oscillator to the timing of environmental cues, and output signals that regulate physiological events within the plant (Harmer 2009). The circadian oscillator includes morning and evening peakexpressing components in a coalesced series of 
repressive feedback loops controlled by at least one key activator (Fogelmark and Troein 2014). For example, reciprocal expression occurs between CCA1 (CIRCADIAN CLOCK-ASSOCIATED 1) and TOC1 (TIMING OF CAB EXPRESSION 1), which display morning and evening expression peaks, respectively (Alabadí et al. 2001). CCA1, a myb-type transcription factor, represses TOC1 expression by binding to an evening regulatory element (CCRE) in the TOC1 promoter. Numerous similar feedback interactions have been mapped within clock functions (Harmer 2009).

In a core oscillator network of tightly controlled, repressive transcription factors, $R E V$ EILLE8 (RVE8), a homolog of CCA1 (and LHY) serves as a primary activator (Fogelmark and Troein 2014). Similar to morning-phased factors, RVE 8 binds to evening-phased genes but functions to activate rather than repress expression (Rawat et al. 2011). Whereas mutations of $C C A 1$ and $L H Y$ shorten clock period, mutations of $R V E$-clade genes lengthen clock pace (Rawat et al. 2011; Gray et al. 2017), reflecting rhythmic robustness of the system (Shalit-Kaneh et al. 2018).

Linked to the oscillation core are environmental sensing networks, with the most prominent entrainment stimuli being light and temperature. Light qualitative and quantitative input signals are conveyed by phytochrome red/ far-red light sensors ( $p h y A, p h y B)$ and cryptochrome ( $c r y$ ) blue light photoreceptors (Somers et al. 1998), which are regulated in both their transcription and photosensitivity by clock functions (Toth et al. 2001). Components also integrate temperature information to the clock, with phyB serving a thermosensory role (Jung et al. 2016; Legris et al. 2016), and clock gene mutation data showing temperature as a clock entrainment stimulus (Heintzen et al. 1994; Thines and Harmon 2010). An important regulatory influence of temperature on clock functions occurs through changes in alternative splicing of several of the clock genes (James et al. 2012; Gil and Park 2019).

Clock output pathways show significant alignment with plant environmental adaptation (Covington et al. 2008). Clock regulation is documented in plant growth, flower induction, photosynthesis, sugar metabolism, nutrient homeostasis, phytohormone signaling, and abiotic and biotic stress responses (Dodd et al. 2005; Covington and Harmer 2007; Greenham and McClung 2015; Sanchez and Kay 2016). Timing of vegetative to reproductive growth transition is influenced by regulators of flowering that show circadian control (Song et al. 2013). Biotic stress-response networks are also integrated to the clock (Goodspeed et al. 2013), as is the cellular regulation of ROS and oxidative stress factors (Lai et al. 2012). Although the details of multinetwork regulation during development and in response to environmental cues are not yet well understood, as much as one-third of the plant transcriptome shows evidence of potential circadian control (Covington et al. 2008). Modulation of $R V E 8$-related loci, interacting with PHYTOCHROME INTERACTING FACTOR4 (PIF4) and PIF5, influence plant growth rate and cell size to increase overall plant biomass and fitness (Gray et al. 2017). These studies, of increasing interest for their agricultural potential, underline the integral role of circadian networks in natural plant adaptation and environmental signal perception (Green et al. 2002).

Plant environmental responsiveness shows a direct, but not yet well detailed, relationship with epigenetic changes in chromatin features (Richards et al. 2017). DNA methylation is a highly dynamic and heterogeneous process across plant cell types, and coordinates with active demethylation activity and transcriptional regulators to effect cell-type differential gene expression and its subsequent cellular and transgenerational memory (Schübeler 2015). In circadian clock-related pathways, DNA methylation and chromatin modifications are associated with alternative splicing of clockrelated genes (Sanchez et al. 2011). Whether gene-associated methylation is a cause or consequence of the splicing behavior is not yet clear. PIF4, an integral component of clock-associated thermomorphogenesis in plants, also shows evidence of epigenetic regulation (Quint et al. 2016). Histone $\mathrm{H} 3$ acetylation and $\mathrm{H} 3 \mathrm{~K} 4$ trimethylation ( $\mathrm{H} 3 \mathrm{~K} 4 \mathrm{me} 3)$ serve as key regulators of the clock oscillator in plants (Malapeira et al. 
2012; Malapeira and Mas 2013). These chromatin modifications can work coordinately to regulate rhythmic changes in transcriptional activity, but also to influence transgenerational behaviors. The salicylic acid induction pathway, for example, is subject to transgenerational priming, such that progeny plants display more rapid and effective response to pathogen attack (Slaughter et al. 2012). In mammals as well, machinery controlling epigenetic behaviors show rhythmic expression, a likely consequence of epigenetic circuitry coevolution with daily and seasonal cycling patterns across life forms (Stevenson 2018).

\section{POTENTIAL FOR AGRICULTURAL ADVANCEMENTS}

The plant kingdom has evolved innumerable strategies for environmental adaptation, many of which become fixed within a species or result in the emergence of new species (Vicient and Casacuberta 2017). However, intraspecific phenotypic plasticity mechanisms that facilitate accelerated evolution following environmental change can offer valuable insights of agricultural value. For example, epigenetic breeding efforts have begun to emerge, exploiting both the epiRIL (Johannes et al. 2009) and MSH1 reprogramming systems (De La Rosa Santamaria et al. 2014; Virdi et al. 2015; Yang et al. 2015; Raju et al. 2018). MSH1-based breeding efforts have produced yield increases of $20 \%-40 \%$ together with enhanced resilence. Genome-wide methylome studies in crop plants offer insight into available epiallelic variation (Rodríguez López and Wilkinson 2015) as well as agronomic traits that are influenced by TE-target gene proximity (Butelli et al. 2012; Khan et al. 2013; OngAbdullah et al. 2015; Hirsch and Springer 2017). Elaboration of the genetic regulation of embryogenesis has permitted successful engineering of asexual, apomictic propagation in rice (Khanday et al. 2019), likely to represent a significant agricultural advancement. Greater resolution of the circadian clock and related gene networks provide strategies for enhancing plant growth and productivity (Gray et al. 2017), as well as stress tolerance (Grundy et al. 2015). The future of plant breeding may very well emerge as an integration process that incorporates high-resolution genomic data with epigenetic, environmental sensory, and growth phenotyping data into a multicomponent selection scheme (Furbank and Tester 2011; Tardieu et al. 2017). As resolution of these mechanisms improves, selection can be adjusted to exploit the many and varied mechanisms employed by each plant species to enhance resilience and maintain energy balance.

\section{ACKNOWLEDGMENTS}

In the interest of space, we recognize that we were not able to mention many important examples of plasticity in plants. We thank Hardik Kundariya for his comments on the text.

\section{REFERENCES}

Abdelnoor RV, Yule R, Elo A, Christensen AC, MeyerGauen G, Mackenzie SA. 2003. Substoichiometric shifting in the plant mitochondrial genome is influenced by a gene homologous to MutS. Proc Natl Acad Sci 100: 5968 5973. doi:10.1073/pnas. 1037651100

Abdelnoor RV, Christensen AC, Mohammed S, Munoz-Castillo B, Moriyama H, Mackenzie SA. 2006. Mitochondrial genome dynamics in plants and animals: Convergent gene fusions of a MutS homologue. J Mol Evol 63: 165173. doi:10.1007/s00239-005-0226-9

Ahmed I, Sarazin A, Bowler C, Colot V, Quesneville H. 2011. Genome-wide evidence for local DNA methylation spreading from small RNA-targeted sequences in Arabidopsis. Nucleic Acids Res 39: 6919-6931. doi:10.1093/nar/ gkr324

Alabadí D, Oyama T, Yanovsky MJ, Harmon FG, Más P, Kay SA. 2001. Reciprocal regulation between TOC1 and LHYl CCA1 within the Arabidopsis circadian clock. Science 293: 880-883. doi:10.1126/science.1061320

Altieri MA, Merrick L. 1987. In situ conservation of crop genetic resources through maintenance of traditional farming systems. Econ Bot 41: 86-96. doi:10.1007/ BF02859354

Arrieta-Montiel MP, Shedge V, Davila J, Christensen AC, Mackenzie SA. 2009. Diversity of the Arabidopsis mitochondrial genome occurs via nuclear-controlled recombination activity. Genetics 183: 1261-1268. doi:10.1534/ genetics.109.108514

Asker SE, Jerling L. 2017. Apomixis in plants. CRC, Boca Raton, FL.

Barah P, Jayavelu ND, Mundy J, Bones AM. 2013. Genome scale transcriptional response diversity among ten ecotypes of Arabidopsis thaliana during heat stress. Front Plant Sci 4: 532. doi:10.3389/fpls.2013.00532 
Beltrán J, Wamboldt Y, Sanchez R, LaBrant EW, Kundariya H, Virdi KS, Elowsky C, Mackenzie SA. 2018. Specialized plastids trigger tissue-specific signaling for systemic stress response in plants. Plant Physiol 178: 672-683. doi:10 $.1104 /$ pp. 18.00804

Bennetzen JL, Wang H. 2014. The contributions of transposable elements to the structure, function, and evolution of plant genomes. Annu Rev Plant Biol 65: 505-530. doi:10.1146/annurev-arplant-050213-035811

Bera S, Sen MK, Banerjee M. 1995. Foraminiferal biozonation in the western margin of the Bengal Basin. Indian J Earth Sci 22: 110-118.

Bouttier M, Laperriere D, Memari B, Mangiapane J, Fiore A, Mitchell E, Verway M, Behr MA, Sladek R, Barreiro LB, et al. 2016. Alu repeats as transcriptional regulatory platforms in macrophage responses to M. tuberculosis infection. Nucleic Acids Res 44: 10571-10587. doi:10.1093/ nar/gkw782

Butelli E, Licciardello C, Zhang Y, Liu J, Mackay S, Bailey P, Reforgiato-Recupero G, Martin C. 2012. Retrotransposons control fruit-specific, cold-dependent accumulation of anthocyanins in blood oranges. Plant Cell 24: 1242 1255. doi:10.1105/tpc.111.095232

Cappadocia L, Maréchal A, Parent JS, Lepage É, Sygusch J, Brisson N. 2010. Crystal structures of DNA-Whirly complexes and their role in Arabidopsis organelle genome repair. Plant Cell 22: 1849-1867. doi:10.1105/tpc.109 .071399

Carman JG. 1997. Asynchronous expression of duplicate genes in angiosperms may cause apomixis, bispory, tetraspory, and polyembryony. Biol J Linn Soc 61: 51-94. doi:10.1111/j.1095-8312.1997.tb01778.x

Caruso CM, Case AL. 2013. Testing models of sex ratio evolution in a gynodioecious plant: Female frequency covaries with the cost of male fertility restoration. Evolution 67: 561-566. doi:10.1111/j.1558-5646.2012.01798.x

Caruso CM, Case AL, Bailey MF. 2012. The evolutionary ecology of cytonuclear interactions in angiosperms. Trends Plant Sci 17: 638-643. doi:10.1016/j.tplants.2012 .06 .006

Case AL, Caruso CM. 2010. A novel approach to estimating the cost of male fertility restoration in gynodioecious plants. New Phytol 186: 549-557. doi:10.1111/j.14698137.2010.03199.x

Chen L, Liu Y-G. 2014. Male sterility and fertility restoration in crops. Annu Rev Plant Biol 65: 579-606. doi:10.1146/ annurev-arplant-050213-040119

Chuong EB, Elde NC, Feschotte C. 2016. Regulatory evolution of innate immunity through co-option of endogenous retroviruses. Science 351: 1083-1087. doi:10.1126/ science.aad5497

Chuong EB, Elde NC, Feschotte C. 2017. Regulatory activities of transposable elements: From conflicts to benefits. Nat Rev Genet 18: 71-86. doi:10.1038/nrg.2016.139

Covington MF, Harmer SL. 2007. The circadian clock regulates auxin signaling and responses in Arabidopsis. PLoS Biol 5: e222. doi:10.1371/journal.pbio.0050222

Covington MF, Maloof JN, Straume M, Kay SA, Harmer SL. 2008. Global transcriptome analysis reveals circadian regulation of key pathways in plant growth and development. Genome Biol 9: R130. doi:10.1186/gb-2008-9-8-r130
Cramer GR, Urano K, Delrot S, Pezzotti M, Shinozaki K. 2011. Effects of abiotic stress on plants: A systems biology perspective. BMC Plant Biol 11: 163. doi:10.1186/14712229-11-163

Davila JI, Arrieta-Montiel MP, Wamboldt Y, Cao J, Hagmann J, Shedge V, Xu YZ, Weigel D, Mackenzie SA. 2011. Double-strand break repair processes drive evolution of the mitochondrial genome in Arabidopsis. BMC Biol 9: 64. doi:10.1186/1741-7007-9-64

De La Rosa Santamaria R, Shao MR, Wang G, Nino-Liu DO, Kundariya H, Wamboldt Y, Dweikat I, Mackenzie SA 2014. MSH1-induced non-genetic variation provides a source of phenotypic diversity in Sorghum bicolor. PLOS ONE 9: e108407. doi:10.1371/journal.pone.0108407

Desveaux D, Subramaniam R, Després C, Mess JN, Lévesque C, Fobert PR, Dangl JL, Brisson N. 2004. A "Whirly" transcription factor is required for salicylic acid-dependent disease resistance in Arabidopsis. Dev Cell 6: 229240. doi:10.1016/S1534-5807(04)00028-0

Desveaux D, Maréchal A, Brisson N. 2005. Whirly transcription factors: Defense gene regulation and beyond. Trends Plant Sci 10: 95-102. doi:10.1016/j.tplants.2004.12.008

Dodd AN, Salathia N, Hall A, Kévei E, Tóth R, Nagy F, Hibberd JM, Millar AJ, Webb AAR. 2005. Cell biology: Plant circadian clocks increase photosynthesis, growth, survival, and competitive advantage. Science 309: 630633. doi:10.1126/science.1115581

Eichten SR, Ellis NA, Makarevitch I, Yeh CT, Gent JI, Guo L, McGinnis KM, Zhang X, Schnable PS, Vaughn MW, et al. 2012. Spreading of heterochromatin is limited to specific families of maize retrotransposons. PLoS Genet 8: e1003127. doi:10.1371/journal.pgen.1003127

El Baidouri M, Panaud O. 2013. Comparative genomic paleontology across plant kingdom reveals the dynamics of TE-driven genome evolution. Genome Biol Evol 5: $954-$ 965. doi:10.1093/gbe/evt025

Evans LT, Knox RB. 1969. Environmental control of reproduction in Themeda australis. Aust J Bot 17: 375-389. doi:10.1071/BT9690375

Feschotte C, Pritham EJ. 2007. DNA transposons and the evolution of eukaryotic genomes. Annu Rev Genet 41: 331-368. doi:10.1146/annurev.genet.40.110405.090448

Filichkin SA, Breton G, Priest HD, Dharmawardhana P, Jaiswal P, Fox SE, Michael TP, Chory J, Kay SA, Mockler TC. 2011. Global profiling of rice and poplar transcriptomes highlights key conserved circadian-controlled pathways and cis-regulatory modules. PLOS ONE 6: e16907. doi:10.1371/journal.pone.0016907

Fogelmark K, Troein C. 2014. Rethinking transcriptional activation in the Arabidopsis circadian clock. PLoS Comput Biol 10: e1003705. doi:10.1371/journal.pcbi.1003705

Foyer CH, Karpinska B, Krupinska K. 2014. The functions of WHIRLY1 and REDOXRESPONSIVE TRANSCRIPTION FACTOR 1 in cross tolerance responses in plants: A hypothesis. Philos Trans R Soc B Biol Sci 369: 20130226. doi:10.1098/rstb.2013.0226

Friedrich T, Faivre L, Bäurle I, Schubert D. 2019. Chromatinbased mechanisms of temperature memory in plants. Plant Cell Environ 42: 762-770. doi:10.1111/pce.13373

Furbank RT, Tester M. 2011. Phenomics-Technologies to relieve the phenotyping bottleneck. Trends Plant Sci 16: 635-644. doi:10.1016/j.tplants.2011.09.005 
X. Yang and S.A. Mackenzie

Gil KE, Park CM. 2019. Thermal adaptation and plasticity of the plant circadian clock. New Phytol 221: 1215-1229. doi:10.1111/nph.15518

Goodspeed D, Chehab EW, Covington MF, Braam J. 2013. Circadian control of jasmonates and salicylates: The clock role in plant defense. Plant Signal Behav 8: e23123. doi:10 $.4161 / \mathrm{psb} .23123$

Gounaris EK, Sherwood RT, Gounaris I, Hamilton RH, Gustine DL. 1991. Inorganic salts modify embryo sac development in sexual and aposporous Cenchrus ciliaris. Sex Plant Reprod 4: 188-192. doi:10.1007/BF00190003

Gray JA, Shalit-Kaneh A, Chu DN, Hsu PY, Harmer SL. 2017. The REVEILLE clock genes inhibit growth of juvenile and adult plants by control of cell size. Plant Physiol 173: 2308-2322. doi:10.1104/pp.17.00109

Green RM, Tingay S, Wang Z-Y, Tobin EM. 2002. Circadian rhythms confer a higher level of fitness to Arabidopsis plants. Plant Physiol 129: 576-584. doi:10.1104/pp .004374

Greenham K, McClung CR. 2015. Integrating circadian dynamics with physiological processes in plants. Nat Rev Genet 16: 598-610. doi:10.1038/nrg3976

Grimanelli D. 2012. Epigenetic regulation of reproductive development and the emergence of apomixis in angiosperms. Curr Opin Plant Biol 15: 57-62. doi:10.1016/j .pbi.2011.10.002

Grundy J, Stoker C, Carré IA. 2015. Circadian regulation of abiotic stress tolerance in plants. Front Plant Sci 6: 648. doi:10.3389/fpls.2015.00648

Gualberto JM, Newton KJ. 2017. Plant mitochondrial genomes: Dynamics and mechanisms of mutation. Annu Rev Plant Biol 68: 225-252. doi:10.1146/annurev-ar plant-043015-112232

Guio L, Barrón MG, González J. 2014. The transposable element Bari-Jheh mediates oxidative stress response in Drosophila. Mol Ecol 23: 2020-2030. doi:10.1111/mec .12711

Harmer SL. 2009. The circadian system in higher plants. Annu Rev Plant Biol 60: 357-377. doi:10.1146/annurev .arplant.043008.092054

Heintzen C, Melzer S, Fischer R, Kappeler S, Apel K, Staiger D. 1994. A light- and temperature-entrained circadian clock controls expression of transcripts encoding nuclear proteins with homology to RNA-binding proteins in meristematic tissue. Plant J 5: 799-813. doi:10.1046/j.1365313X.1994.5060799.x

Hirsch CD, Springer NM. 2017. Transposable element influences on gene expression in plants. Biochim Biophys Acta Gene Regul Mech 1860: 157-165. doi:10.1016/j .bbagrm.2016.05.010

Hoen DR, Bureau TE. 2012. Transposable element exaptation in plants. Top Curr Genet 24: 219-251. doi:10.1007/ 978-3-642-31842-9_12

Hruz T, Laule O, Szabo G, Wessendorp F, Bleuler S, Oertle L, Widmayer P, Gruissem W, Zimmermann P. 2008. Genevestigator V3: A reference expression database for the meta-analysis of transcriptomes. Adv Bioinformatics 2008: $1-5$. doi: $10.1155 / 2008 / 420747$

Isemer R, Mulisch M, Schäfer A, Kirchner S, Koop HU, Krupinska K. 2012. Recombinant Whirly1 translocates from transplastomic chloroplasts to the nucleus. FEBS Lett 586: 85-88. doi:10.1016/j.febslet.2011.11.029

James AB, Syed NH, Bordage S, Marshall J, Nimmo GA, Jenkins GI, Herzyk P, Brown JWS, Nimmo HG. 2012. Alternative splicing mediates responses of the Arabidopsis circadian clock to temperature changes. Plant Cell 24: 961-981. doi:10.1105/tpc.111.093948

Johannes F, Porcher E, Teixeira FK, Saliba-Colombani V, Simon M, Agier N, Bulski A, Albuisson J, Heredia F, Audigier P, et al. 2009. Assessing the impact of transgenerational epigenetic variation on complex traits. PLoS Genet 5: e1000530. doi:10.1371/journal.pgen.1000530

Joly-Lopez Z, Bureau TE. 2018. Exaptation of transposable element coding sequences. Curr Opin Genet Dev 49: 3442. doi:10.1016/j.gde.2018.02.011

Joly-Lopez Z, Forczek E, Vello E, Hoen DR, Tomita A, Bureau TE. 2017. Abiotic stress phenotypes are associated with conserved genes derived from transposable elements. Front Plant Sci 8: 2027. doi:10.3389/fpls.2017 .02027

Jung JH, Domijan M, Klose C, Biswas S, Ezer D, Gao M, Khattak AK, Box MS, Charoensawan V, Cortijo S, et al. 2016. Phytochromes function as thermosensors in Arabidopsis. Science 354: 886-889. doi:10.1126/science.aaf6005

Kaul S, Koo HL, Jenkins J, Rizzo M, Rooney T, Tallon LJ, Feldblyum T, Nierman W, Benito MI, Lin X, et al. 2000. Analysis of the genome sequence of the flowering plant Arabidopsis thaliana. Nature 408: 796-815. doi:10.1038/ 35048692

Kenchanmane Raju SK, Shao MR, Wamboldt Y, Mackenzie S. 2018. Epigenomic plasticity of Arabidopsis msh1 mutants under prolonged cold stress. Plant Direct 2: e00079. doi:10.1002/pld3.79

Khan AR, Enjalbert J, Marsollier AC, Rousselet A, Goldringer I, Vitte C. 2013. Vernalization treatment induces site-specific DNA hypermethylation at the VERNALIZATION-A1 (VRN-A1) locus in hexaploid winter wheat. BMC Plant Biol 13. doi:10.1186/1471-2229-13-209

Khanday I, Skinner D, Yang B, Mercier R, Sundaresan V. 2019. A male-expressed rice embryogenic trigger redirected for asexual propagation through seeds. Nature 565: 91-95. doi:10.1038/s41586-018-0785-8

Klatt S, Hadacek F, Hodač L, Brinkmann G, Eilerts M, Hojsgaard D, Hörandl E. 2016. Photoperiod extension enhances sexual megaspore formation and triggers metabolic reprogramming in facultative apomictic Ranunculus auricomus. Front Plant Sci 7: 278. doi:10.3389/fpls.2016 .00278

Knox RB. 1967. Apomixis: Seasonal and population differences in a grass. Science 157: 325-326. doi:10.1126/sci ence.157.3786.325

Kobayashi Y, Takusagawa M, Harada N, Fukao Y, Yamaoka S, Kohchi T, Hori K, Ohta H, Shikanai T, Nishimura Y. 2016. Eukaryotic components remodeled chloroplast nucleoid organization during the green plant evolution. Genome Biol Evol 8: 1-16. doi:10.1093/gbe/evv233

Koltunow AM, Grossniklaus U. 2003. Apomixis: A developmental perspective. Annu Rev Plant Biol 54: 547-574. doi:10.1146/annurev.arplant.54.110901.160842

Koltunow AMG, Johnson SD, Rodrigues JCM, Okada T, Hu Y, Tsuchiya T, Wilson S, Fletcher P, Ito K, Suzuki G, et al. 2011. Sexual reproduction is the default mode in apomic- 
tic Hieracium subgenus Pilosella, in which two dominant loci function to enable apomixis. Plant J 66: 890-902. doi:10.1111/j.1365-313X.2011.04556.x

Kooke R, Johannes F, Wardenaar R, Becker F, Etcheverry M, Colot V, Vreugdenhil D, Keurentjes JJB. 2015. Epigenetic basis of morphological variation and phenotypic plasticity in Arabidopsis thaliana. Plant Cell Online 27: 337-348. doi:10.1105/tpc.114.133025

Krause K, Kilbienski I, Mulisch M, Rödiger A, Schäfer A, Krupinska K. 2005. DNA-binding proteins of the Whirly family in Arabidopsis thaliana are targeted to the organelles. FEBS Lett 579: 3707-3712. doi:10.1016/j.febslet .2005 .05 .059

Lai AG, Doherty CJ, Mueller-Roeber B, Kay SA, Schippers JHM, Dijkwel PP. 2012. CIRCADIAN CLOCK-ASSOCIATED 1 regulates ROS homeostasis and oxidative stress responses. Proc Natl Acad Sci 109: 17129-17134. doi:10 $.1073 /$ pnas. 1209148109

Le TN, Miyazaki Y, Takuno S, Saze H. 2015. Epigenetic regulation of intragenic transposable elements impacts gene transcription in Arabidopsis thaliana. Nucleic Acids Res 43: 3911-3921. doi:10.1093/nar/gkv258

Lee HE, Ayarpadikannan S, Kim HS. 2015. Role of transposable elements in genomic rearrangement, evolution, gene regulation and epigenetics in primates. Genes Genet Syst 90: 245-257. doi:10.1266/ggs.15-00016

Legris M, Klose C, Burgie ES, Rojas CC, Neme M, Hiltbrunner A, Wigge PA, Schäfer E, Vierstra RD, Casal JJ. 2016 Phytochrome B integrates light and temperature signals in Arabidopsis. Science 354: 897-900. doi:10.1126/science .aaf5656

Li Q, Gent JI, Zynda G, Song J, Makarevitch I, Hirsch CD, Hirsch CN, Dawe RK, Madzima TF, McGinnis KM, et al. 2015. RNA-directed DNA methylation enforces boundaries between heterochromatin and euchromatin in the maize genome. Proc Natl Acad Sci 112: 14728-14733. doi:10.1073/pnas.1514680112

Lisch D. 2013. How important are transposons for plant evolution? Nat Rev Genet 14: 49-61. doi:10.1038/nrg3374

Lisch D, Slotkin RK. 2011. Strategies for silencing and escape. The ancient struggle between transposable elements and their hosts. Int Rev Cell Mol Biol 292: 119-152. doi:10 .1016/B978-0-12-386033-0.00003-7

Makarevitch I, Waters AJ, West PT, Stitzer M, Hirsch CN, Ross-Ibarra J, Springer NM. 2015. Transposable elements contribute to activation of maize genes in response to abiotic stress. PLoS Genet 11: e1004915. doi:10.1371/jour nal.pgen.1004915

Malapeira J, Mas P. 2013. A chromatin-dependent mechanism regulates gene expression at the core of the Arabidopsis circadian clock. Plant Signal Behav 8: e24079. doi:10.4161/psb.24079

Malapeira J, Khaitova LC, Mas P. 2012. Ordered changes in histone modifications at the core of the Arabidopsis circadian clock. Proc Natl Acad Sci 109: 21540-21545. doi:10.1073/pnas.1217022110

Marechal A, Parent JS, Veronneau-Lafortune F, Joyeux A, Lang BF, Brisson N. 2009. Whirly proteins maintain plastid genome stability in Arabidopsis. Proc Natl Acad Sci 106: 14693-14698. doi:10.1073/pnas.0901710106

Martin A, Troadec C, Boualem A, Rajab M, Fernandez R, Morin H, Pitrat M, Dogimont C, Bendahmane A. 2009. A transposon-induced epigenetic change leads to sex determination in melon. Nature 461: 1135-1138. doi:10.1038/ nature 08498

Melonek J, Mulisch M, Schmitz-Linneweber C, Grabowski E, Hensel G, Krupinska K. 2010. Whirly1 in chloroplasts associates with intron containing RNAs and rarely colocalizes with nucleoids. Planta 232: 471-481. doi:10 .1007/s00425-010-1183-0

Melonek J, Oetke S, Krupinska K. 2016. Multifunctionality of plastid nucleoids as revealed by proteome analyses. Biochim Biophys Acta 1864: 1016-1038. doi:10.1016/j .bbapap.2016.03.009

Mieczkowski PA, Lemoine FJ, Petes TD. 2006. Recombination between retrotransposons as a source of chromosome rearrangements in the yeast Saccharomyces cerevisiae. DNA Repair (Amst) 5: 1010-1020. doi:10.1016/j .dnarep.2006.05.027

Morgado L, Preite V, Oplaat C, Anava S, De Carvalho JF, Rechavi O, Johannes F, Verhoeven KJF. 2017. Small RNAs reflect grandparental environments in apomictic dandelion. Mol Biol Evol 34: 2035-2040. doi:10.1093/molbev/ $\operatorname{msx} 150$

Naito K, Zhang F, Tsukiyama T, Saito H, Hancock CN, Richardson AO, Okumoto Y, Tanisaka T, Wessler SR. 2009. Unexpected consequences of a sudden and massive transposon amplification on rice gene expression. Nature 461: 1130-1134. doi:10.1038/nature08479

Nedelcu AM, Marcu O, Michod RE. 2004. Sex as a response to oxidative stress: A twofold increase in cellular reactive oxygen species activates sex genes. Proc R Soc B Biol Sci 271: 1591-1596. doi:10.1098/rspb.2004.2747

Oberlin S, Sarazin A, Chevalier C, Voinnet O, Marí-Ordóñez A. 2017. A genome-wide transcriptome and translatome analysis of Arabidopsis transposons identifies a unique and conserved genome expression strategy for Ty1/Copia retroelements. Genome Res 27: 1549-1562. doi:10.1101/ gr.220723.117

Oliver KR, McComb JA, Greene WK. 2013. Transposable elements: Powerful contributors to angiosperm evolution and diversity. Genome Biol Evol 5: 1886-1901. doi:10 $.1093 /$ gbe/evt141

Olmedo-Monfil V, Durán-Figueroa N, Arteaga-Vázquez M, Demesa-Arévalo E, Autran D, Grimanelli D, Slotkin RK, Martienssen RA, Vielle-Calzada JP. 2010. Control of female gamete formation by a small RNA pathway in Arabidopsis. Nature 464: 628-632. doi:10.1038/nature08828

Ong-Abdullah M, Ordway JM, Jiang N, Ooi SE, Kok SY, Sarpan N, Azimi N, Hashim AT, Ishak Z, Rosli SK, et al. 2015. Loss of Karma transposon methylation underlies the mantled somaclonal variant of oil palm. Nature 525: 533-537. doi:10.1038/nature 15365

Pfalz J, Pfannschmidt T. 2015. Plastid nucleoids: Evolutionary reconstruction of a DNA/protein structure with prokaryotic ancestry. Front Plant Sci 6: 220. doi:10.3389/fpls .2015 .00220

Prikryl J, Watkins KP, Friso G, van Wijk KJ, Barkan A. 2008. A member of the Whirly family is a multifunctional RNA- and DNA-binding protein that is essential for chloroplast biogenesis. Nucleic Acids Res 36: 5152-5165. doi:10.1093/nar/gkn492

Quint M, Delker C, Franklin KA, Wigge PA, Halliday KJ, Van Zanten M. 2016. Molecular and genetic control of 
plant thermomorphogenesis. Nat Plants 2: 15190. doi:10 $.1038 /$ nplants.2015.190

Raju SKK, Shao MR, Sanchez R, Xu YZ, Sandhu A, Graef G, Mackenzie S. 2018. An epigenetic breeding system in soybean for increased yield and stability. Plant Biotechnol J 16: 1836-1847. doi:10.1111/pbi.12919

Rawat R, Takahashi N, Hsu PY, Jones MA, Schwartz J, Salemi MR, Phinney BS, Harmer SL. 2011. REVEILLE8 and PSEUDO-REPONSE REGULATOR5 form a negative feedback loop within the arabidopsis circadian clock. PLoS Genet 7: e1001350. doi:10.1371/journal.pgen.100 1350

Richards CL, Alonso C, Becker C, Bossdorf O, Bucher E, Colomé-Tatché M, Durka W, Engelhardt J, Gaspar B, Gogol-Döring A, et al. 2017. Ecological plant epigenetics: Evidence from model and non-model species, and the way forward. Ecol Lett 20: 1576-1590. doi:10.1111/ele .12858

Rodrigo JM, Zappacosta DC, Selva JP, Garbus I, Albertini E, Echenique V. 2017. Apomixis frequency under stress conditions in weeping lovegrass (Eragrostis curvula). PLoS ONE 12: e0175852. doi:10.1371/journal.pone.0175852

Rodriguez-Leal D, Vielle-Calzada JP. 2012. Regulation of apomixis: Learning from sexual experience. Curr Opin Plant Biol 15: 549-555. doi:10.1016/j.pbi.2012.09.005

Rodríguez López CM, Wilkinson MJ. 2015. Epi-fingerprinting and epi-interventions for improved crop production and food quality. Front Plant Sci 6: 397. doi:10.3389/fpls .2015 .00397

Sahebi M, Hanafi MM, van Wijnen AJ, Rice D, Rafii MY, Azizi P, Osman M, Taheri S, Bakar MFA, Isa MNM, et al. 2018. Contribution of transposable elements in the plant's genome. Gene 665: 155-166. doi:10.1016/j.gene .2018.04.050

Sanchez SE, Kay SA. 2016. The plant circadian clock: From a simple timekeeper to a complex developmental manager. Cold Spring Harb Perspect Biol 8: a027748. doi:10.1101/ cshperspect.a027748

Sanchez SE, Petrillo E, Kornblihtt AR, Yanovsky MJ. 2011. Alternative splicing at the right time. RNA Biol 8: 954959. doi:10.4161/rna.8.6.17336

Sandhu APS, Abdelnoor RV, Mackenzie SA. 2007. Transgenic induction of mitochondrial rearrangements for cytoplasmic male sterility in crop plants. Proc Natl Acad Sci 104: 1766-1770. doi:10.1073/pnas.0609344104

Sato N, Terasawa K, Miyajima K, Kabeya Y. 2003. Organization, developmental dynamics, and evolution of plastid nucleoids. Int Rev Cytol 232: 217-262. doi:10.1016/ S0074-7696(03)32006-6

Schübeler D. 2015. Function and information content of DNA methylation. Nature 517: 321-326. doi:10.1038/na ture14192

Secco D, Wang C, Shou H, Schultz MD, Chiarenza S, Nussaume L, Ecker JR, Whelan J, Lister R. 2015. Stress induced gene expression drives transient DNA methylation changes at adjacent repetitive elements. eLife 4: e09343. doi:10.7554/eLife.09343

Shalit-Kaneh A, Kumimoto RW, Filkov V, Harmer SL. 2018. Multiple feedback loops of the Arabidopsis circadian clock provide rhythmic robustness across environmental conditions. Proc Natl Acad Sci 115: 7147-7152. doi:10 $.1073 /$ pnas. 1805524115
Shao MR, Kumar Kenchanmane Raju S, Laurie JD, Sanchez R, Mackenzie SA. 2017. Stress-responsive pathways and small RNA changes distinguish variable developmental phenotypes caused by MSH1 loss. BMC Plant Biol 17: 47. doi:10.1186/s12870-017-0996-4

Shedge V, Davila J, Arrieta-Montiel MP, Mohammed S, Mackenzie SA. 2010. Extensive rearrangement of the Arabidopsis mitochondrial genome elicits cellular conditions for thermotolerance. Plant Physiol 152: 1960-1970. doi:10.1104/pp.109.152827

Singh M, Goel S, Meeley RB, Dantec C, Parrinello H, Michaud C, Leblanc O, Grimanelli D. 2011. Production of viable gametes without meiosis in maize deficient for an ARGONAUTE protein. Plant Cell 23: 443-458. doi:10 $.1105 /$ tpc. 110.079020

Slaughter A, Daniel X, Flors V, Luna E, Hohn B, MauchMani B. 2012. Descendants of primed Arabidopsis plants exhibit resistance to biotic stress. Plant Physiol 158: 835843. doi:10.1104/pp.111.191593

Somers DE, Devlin PF, Kay SA. 1998. Phytochromes and cryptochromes in the entrainment of the Arabidopsis circadian clock. Science 282: 1488-1490. doi:10.1126/sci ence.282.5393.1488

Song YH, Ito S, Imaizumi T. 2013. Flowering time regulation: Photoperiod- and temperature-sensing in leaves. Trends Plant Sci 18: 575-583. doi:10.1016/j.tplants.2013 .05 .003

Stevenson TJ. 2018. Epigenetic regulation of biological rhythms: An evolutionary ancient molecular timer. Trends Genet 34: 90-100. doi:10.1016/j.tig.2017.11.003

Studer A, Zhao Q, Ross-Ibarra J, Doebley J. 2011. Identification of a functional transposon insertion in the maize domestication gene tb1. Nat Genet 43: 1160-1163. doi:10 $.1038 /$ ng. 942

Tardieu F, Cabrera-Bosquet L, Pridmore T, Bennett M. 2017. Plant phenomics, from sensors to knowledge. Curr Biol 27: R770-R783. doi:10.1016/j.cub.2017.05.055

Thines B, Harmon FG. 2010. Ambient temperature response establishes ELF3 as a required component of the core Arabidopsis circadian clock. Proc Natl Acad Sci 107: 3257-3262. doi:10.1073/pnas.0911006107

Toth R, Kevei E, Hall A, Millar AJ, Nagy F, Kozma-Bognar L. 2001. Circadian clock-regulated expression of phytochrome and cryptochrome genes in Arabidopsis. Plant Physiol 127: 1607-1616. doi:10.1104/pp.010467

Tsuchiya T, Eulgem T. 2013. An alternative polyadenylation mechanism coopted to the Arabidopsis RPP7 gene through intronic retrotransposon domestication. Proc Natl Acad Sci 110: E3535-E3543. doi:10.1073/pnas .1312545110

Verhoeven KJF, Van Dijk PJ, Biere A. 2010. Changes in genomic methylation patterns during the formation of triploid asexual dandelion lineages. Mol Ecol 19: 315324. doi:10.1111/j.1365-294X.2009.04460.x

Vicient CM, Casacuberta JM. 2017. Impact of transposable elements on polyploid plant genomes. Ann Bot 120: 195207. doi:10.1093/aob/mcx078

Virdi KS, Laurie JD, Xu YZ, Yu J, Shao MR, Sanchez R, Kundariya H, Wang D, Riethoven JJM, Wamboldt Y, et al. 2015. Arabidopsis MSH1 mutation alters the epigenome and produces heritable changes in plant growth. Nat Commun 6: 6386. doi:10.1038/ncomms7386 
Virdi KSS, Wamboldt Y, Kundariya H, Laurie JDD, Keren I, Kumar KRS, Block A, Basset G, Luebker S, Elowsky C, et al. 2016. MSH1 is a plant organellar DNA binding and thylakoid protein under precise spatial regulation to alter development. Mol Plant 9: 245-260. doi:10.1016/j.molp .2015.10.011

Wang G, Köhler C. 2017. Epigenetic processes in flowering plant reproduction. J Exp Bot 68: 797-807.

Weinhold A. 2018. Transgenerational stress-adaption: An opportunity for ecological epigenetics. Plant Cell Rep 37: 3-9. doi:10.1007/s00299-017-2216-y

Weiss M. 2013. Resource-related diversification and its measures-Review of empirical results. Probl Perspect Manag 11: 76-85.

Wendel JF, Jackson SA, Meyers BC, Wing RA. 2016. Evolution of plant genome architecture. Genome Biol 17: 37. doi:10.1186/s13059-016-0908-1

West PT, Li Q, Ji L, Eichten SR, Song J, Vaughn MW, Schmitz RJ, Springer NM. 2014. Genomic distribution of $\mathrm{H} 3 \mathrm{~K} 9 \mathrm{me} 2$ and DNA methylation in a maize genome. PLoS ONE 9: e105267. doi:10.1371/journal.pone.0105267

Williams BP, Pignatta D, Henikoff S, Gehring M. 2015. Methylation-sensitive expression of a DNA demethylase gene serves as an epigenetic rheostat. PLoS Genet 11: e1005142. doi:10.1371/journal.pgen.1005142

Willis JH. 1999. The contribution of male-sterility mutations to inbreeding depression in Mimulus guttatus. Heredity (Edinb) 83: 337-346. doi:10.1038/sj.hdy.6885790

Xu YZ, Arrieta-Montiel MP, Virdi KS, de Paula WBM, Widhalm JR, Basset GJ, Davila JI, Elthon TE, Elowsky CG, Sato SJ, et al. 2011. MutS HOMOLOG1 is a nucleoid protein that alters mitochondrial and plastid properties and plant response to high light. Plant Cell Online 23: 3428-3441. doi:10.1105/tpc.111.089136

Xu YZ, Santamaria Rde L, Virdi KS, Arrieta-Montiel MP, Razvi F, Li S, Ren G, Yu B, Alexander D, Guo L, et al. 2012. The chloroplast triggers developmental reprogramming when mutS HOMOLOG1 is suppressed in plants. Plant Physiol 159: 710-720. doi:10.1104/pp.112.196055

Yang X, Kundariya H, Xu YZ, Sandhu A, Yu J, Hutton SF, Zhang M, Mackenzie SA. 2015. MutS HOMOLOG1derived epigenetic breeding potential in tomato. Plant Physiol 168: 222-232. doi:10.1104/pp.15.00075

Yoo HH, Kwon C, Lee MM, Chung IK. 2007. Single-stranded DNA binding factor AtWHY1 modulates telomere length homeostasis in Arabidopsis. Plant J 49: 442-451. doi:10.1111/j.1365-313X.2006.02974.x

Zabala G, Vodkin LO. 2014. Methylation affects transposition and splicing of a large CACTA transposon from a MYB transcription factor regulating anthocyanin synthase genes in soybean seed coats. PLOS ONE 9: e111959. doi:10.1371/journal.pone.0111959

Zamudio N, Bourc'His D. 2010. Transposable elements in the mammalian germline: A comfortable niche or a deadly trap. Heredity (Edinb) 105: 92-104. doi:10.1038/hdy .2010 .53

Zhao N, Xu X, Wamboldt Y, Mackenzie SA, Yang X, Hu Z, Yang J, Zhang M. 2016. MutS HOMOLOG1 silencing mediates ORF220 substoichiometric shifting and causes male sterility in Brassica juncea. J Exp Bot 67: 435-444. doi:10.1093/jxb/erv480

Zuellig MP, Kenney AM, Sweigart AL. 2014. Evolutionary genetics of plant adaptation: Insights from new model systems. Curr Opin Plant Biol 18: 44-50. doi:10.1016/j .pbi.2014.01.001 


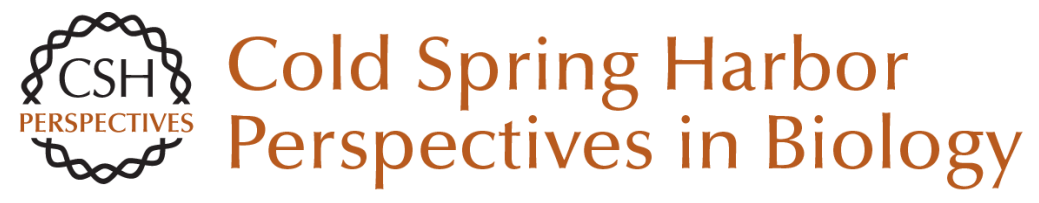

\section{Many Facets of Dynamic Plasticity in Plants}

Xiaodong Yang and Sally A. Mackenzie

Cold Spring Harb Perspect Biol 2019; doi: 10.1101/cshperspect.a034629 originally published online May 28,2019

\section{Subject Collection Engineering Plants for Agriculture}

Plant Inflorescence Architecture: The Formation, Activity, and Fate of Axillary Meristems Yang Zhu and Doris Wagner

Sub1 Rice: Engineering Rice for Climate Change Kyle Emerick and Pamela C. Ronald

Engineering Disease-Resistant Cassava Z.J. Daniel Lin, Nigel J. Taylor and Rebecca Bart

Many Facets of Dynamic Plasticity in Plants Xiaodong Yang and Sally A. Mackenzie

How Do Strigolactones Ameliorate Nutrient Deficiencies in Plants?

Kaori Yoneyama

Mechanisms and Impact of Symbiotic Phosphate Acquisition Chai Hao Chiu and Uta Paszkowski
The Sweet Side of Plant-Specialized Metabolism Thomas Louveau and Anne Osbourn

The Role of Dwarfing Traits in Historical and Modern Agriculture with a Focus on Rice Ángel Ferrero-Serrano, Christian Cantos and Sarah M. Assmann

Bt Brinjal in Bangladesh: The First Genetically Engineered Food Crop in a Developing Country Anthony M. Shelton, Md. J. Hossain, Vijay Paranjape, et al.

Circadian Rhythms in Plants Nicky Creux and Stacey Harmer

Developing Blight-Tolerant American Chestnut Trees William A. Powell, Andrew E. Newhouse and Vernon Coffey

Stomatal Development and Perspectives toward Agricultural Improvement Hitoshi Endo and Keiko U. Torii

For additional articles in this collection, see http://cshperspectives.cshlp.org/cgi/collection/

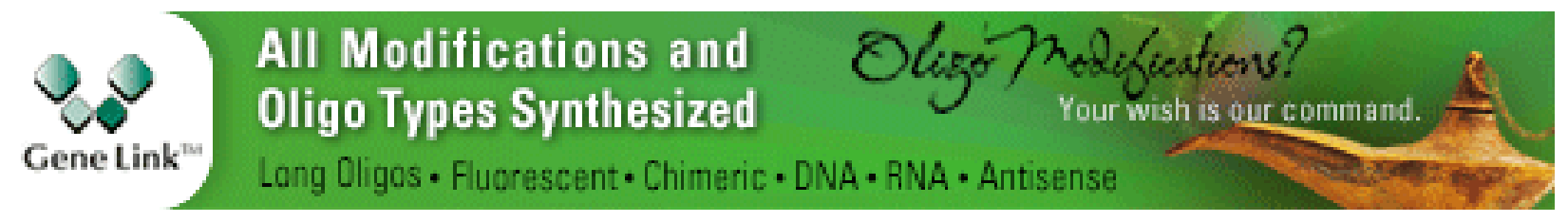

